\section{Advancing Sustainability in Tree Crop Pest Management: Refining Spray Application Rate with a Laser-guided Variable-rate Sprayer in Apple Orchards}

\author{
Lauren Fessler, Amy Fulcher, and Dave Lockwood \\ Department of Plant Sciences, University of Tennessee, Knoxville, TN 37996
}

Wesley Wright

Department of Biosystems Engineering and Soil Science, University of Tennessee, Knoxville, TN 37996

\section{Heping Zhu \\ Application Technology Research Unit, U.S. Department of Agriculture- Agricultural Research Service, Wooster, OH 44691}

Additional index words. intelligent sprayer, off-target spray, orchard, pesticide, specialty crops, spray drift

\begin{abstract}
Advanced variable-rate spray technology, which applies pesticides based on real-time scanning laser rangefinder measurements of plant presence, size, and density, was developed and retrofitted to existing sprayers. Experiments were conducted to characterize the application of four programmed spray rates $(0.03,0.05,0.07$, or 0.09 $\mathbf{L} \cdot \mathbf{m}^{-3}$ of crop geometric volume) when applied to Malus domestica Borkh. 'Golden Delicious' apple trees using this crop sensing technology. Water-sensitive cards (WSCs) were used as samplers to quantify spray coverage, deposits, and deposit density in the target and nontarget areas, and an overspray index based on a threshold of greater than $30 \%$ coverage was calculated. The application rate ranged from 262 $\mathrm{L} \cdot \mathrm{ha}^{-1}$ at the programmed spray rate of $0.03 \mathrm{~L} \cdot \mathrm{m}^{-3}$ to $638 \mathrm{~L} \cdot \mathrm{ha} \mathrm{a}^{-1}$ at the rate of 0.09 $\mathbf{L} \cdot \mathbf{m}^{-3}$. For a given WSC position, spray coverage and deposits increased as the spray rate increased. WSC positions 1 and 2 were oversprayed at all rates. The effect of spray rate on deposit density varied with WSC positions, with high densities achieved by low spray rates for WSCs closest to the sprayer but by high spray rates for WSCs positioned either deeper within or under the canopy. When coalescing deposits were accounted for, deposit densities met or exceeded the recommended pesticide application thresholds (insecticides $20-30$ droplets $/ \mathrm{cm}^{2}$; fungicides $50-70$ droplets $/ \mathrm{cm}^{2}$ ) at all WSC positions for each spray rate tested. The lowest spray rate reduced off-target loss to the orchard floor by $81 \%$ compared with the highest rate, dramatically reducing potential exposure to nontarget organisms, such as foraging pollinators, to come into contact with pesticide residues. Applying the lowest rate of $0.03 \mathrm{~L} \cdot \mathrm{m}^{-3}$ met deposit density efficacy levels while reducing spray volume by $83 \%$ compared with the orchard standard application of $1540 \mathrm{~L} \cdot \mathrm{ha}^{-1}$ and by $87 \%$ compared with the $1950 \mathrm{~L} \cdot \mathrm{ha}^{-1}$ application rate recommended when using the tree row volume method. Thus, there is potential for growers to refine pesticide application rates to further achieve significant pesticide cost savings. Producers of other woody crops, such as nursery, citrus, and grapes, who use air-assisted sprayers, may be able to achieve similar savings by refining pesticide applications through the use of laser rangefinder-based spray application technology.
\end{abstract}

In orchard and nursery production, severe destruction can be caused by certain pests such as plant diseases, e.g., bitter rot [Colletotrichum gloeosporioides (Penz.) Penz. and Sacc. and Glomerella cingulata (Stoneman) Spauld. and H. Schrenk] and fire blight [Erwinia amylovora (Burrill) Winslow et al.] (Jones and Benson, 2001; Sutton et al., 2014), and insects, including trunk and shoot borers (Frank et al., 2013; Seagraves et al., 2013). As a consequence, growers traditionally applied pesticides lib- volumes of spray solution are applied by airassisted sprayers to ensure adequate spray deposition in the interior of the canopy, regardless of whether the tree is positioned in an exterior or interior row (Zhu et al., 2017). Conventional air-assisted ("airblast") sprayers are the typical choice for pesticide application in orchards and nurseries. Airassisted sprayers are typically used to spray an entire farm at a constant rate (i.e., a set number of liters per hectare), regardless of variation in tree size or canopy characteristics (Hong et al., 2018), and these have been repeatedly shown to have considerable losses due to off-target spray and drift (Kasner et al., 2018; Nuyttens et al., 2011). In a comparison between total estimated leaf target and actual spray deposition in an orchard, $43 \%$ of the total amount sprayed by a traditional axial sprayer was applied to the foliage (Duga et al., 2015). Similarly, in a nursery, less than $30 \%$ of spray volume applied with a conventional air-assisted sprayer was deposited ontarget, in spite of it being midseason and foliage from adjacent trees overlapping ( $\mathrm{Zhu}$ et al., 2008). Hołownicki et al. (2000) found that $39.1 \%$ of the total volume applied to semi-dwarf apples is lost to the soil and air. Other research concluded that a total of $43 \%$ to $61 \%$ of total applied spray was lost to the ground (Cross et al., 2001a, 2001b). For conventional orchard sprayers, off-target ground deposition was detectable at $30 \mathrm{~m}$ and airborne drift was measurable $10 \mathrm{~m}$ from the spray area and $6 \mathrm{~m}$ above the ground (Grella et al., 2017). While much of the offtarget ground deposition reported by Cross et al. (2001a, 2001b) was within $4.6 \mathrm{~m}$ of the intended tree row, similar to results from $\mathrm{Zhu}$ et al. (2008), off-target ground losses and drift have been detected more than $50 \mathrm{~m}$ from the target area (Buisman et al., 1989; Kasner et al., 2018). This distance is more than 1.5 times greater than the recommended $30-\mathrm{m}$ Application Exclusion Zone for orchard sprayers as defined by the Worker Protection Standard (Fishel and Sanchez, 2016). At $30 \mathrm{~m}$ from an axial fan airblast sprayer application, an individual would be exposed to 39 times the background level of particle mass concentration (Blanco et al., 2019).

While pesticide applications are necessary to maintain healthy, saleable crops, large volumes of pesticides and off-target applications can have numerous deleterious effects. Pesticide pollution has been observed in air, water (e.g., rivers, drinking water, surface water, and groundwater), and soil (Kim et al., 2017). Additional environmental impacts include biodiversity losses, increased pesticide resistance, and loss of natural enemies and pollinators (Koleva et al., 2011). Human health impacts can result from occupational exposure or contaminated food and drinking water. While there are various factors that influence how pesticide exposure effects human health, studies have linked pesticides to a number of diseases including asthma, diabetes, and multiple types of cancer (Kim et al., 2017). Koleva et al. (2011) state that the costs associated with environmental 
damages and human health impacts total 12.5 billion dollars annually in the United States. Pesticide exposure can be reduced by using well-maintained, appropriate spray equipment, especially that which reduces spray drift (Damalas and Eleftherohorinos, 2011). Reduction in total pesticides applied and offtarget applications would benefit the overall health of humans, particularly applicators and other farm workers, and the environment, while helping to ease the financial burden of production inputs.

To combat the known inefficiency of airassisted sprayers, enhanced sprayers have been developed. These sprayers use various methods to increase sprayer efficiency including variable air assistance (Hołownicki et al., 2017) and technology to detect tree size and shape using ultrasonic sensors (Stajnko et al., 2012) and Red Green Blue color model cameras (Hočevar et al., 2010). Chen et al. (2012) developed an intelligent, laser-guided sprayer designed for orchard, vineyard, and nursery applications. This variable-rate spray technology applies pesticides based on realtime scanning laser rangefinder measurements of plant presence, size, and density. When used to spray apple trees at three foliage stages, i.e., leafing, half-, and fullfoliage, the prototype of this system reduced spray loss to the orchard floor by $93 \%, 93 \%$, and $90 \%$, respectively, and off-target aerial losses by $80 \%, 57 \%$, and $59 \%$, respectively, compared with a conventional radial air-blast sprayer (that applied essentially a half rate, $443 \mathrm{~L} \cdot \mathrm{ha}^{-1}$ ) and was able to maintain uniform spray deposition within the canopy at all stages (Chen et al., 2013a, 2013b). Chen et al. (2019) found that even in nurseries with multiple rows of trees per block, retrofitting this intelligent spray technology to existing air-assisted sprayers reduced the volume applied by more than $50 \%$. This technology allows growers to select the desired spray rate based on liters of spray mixture per cubic meter of crop volume from the safety of the tractor cab. However, no optimal spray rate has been established for apple trees using this technology. The objective of this research was to characterize spray application of this

Received for publication 7 Apr. 2020. Accepted for publication 13 July 2020.

Published online 13 August 2020.

Financial support was provided by TENN Hatch 1009630 and USDA NIFA SCRI Project 201551181-24253. Oren Wooden's Apple House in Pikeville, Tennessee generously provided facilities, labor, and resources that made this research possible.

We thank Mark Burnett, Adam Clark, Jeff McHugh, Grace Pietsch, Arnold Saxton, Xiaocun Sun, Mason Wright, Whitney Yeary, and Randy Zondag for their assistance; and Zach Hansen, Anthony LeBude, and Larry Steckel for their review of an earlier draft of this manuscript.

A.F. is the corresponding author. E-mail: afulcher@ utk.edu.

This is an open access article distributed under the CC BY-NC-ND license (https://creativecommons.org/ licenses/by-nc-nd/4.0/). intelligent spray technology at four spray rates, with the goal of refining spray rate recommendations for tree crops.

\section{Materials and Methods}

An air-assisted trailer sprayer (Model \#1000 CS, AgTec; Superb Horticulture, Plymouth, IN) retrofitted with a laser-guided variable-rate control system (Fig. 1) was used for the experiment. Major components of the original sprayer are a centrifugal pump, a squirrel-cage blower fan, a fluid flow metering assembly, a 3785-L spray tank, and four spray heads (Superb Horticulture, 1994). The centrifugal pump is driven by the tractor power take-off to discharge the spray mixture. Bypass flow from the pump is used to agitate the mixture in the spray tank. Nozzle flow rates are controlled by the orifice size on the plate in the fluid flow metering assembly (Accu-rate metering system with stainless steel metering plates). Each spray nozzle contains a 2-hole air-shear tip to discharge spray mixture that is atomized into droplets of $45 \mu \mathrm{m}$ mass-median-diameter by highspeed air flow from the air blower (Superb Horticulture, 1994). Because of the air shearing method to atomize spray liquids for this sprayer, droplet sizes varied with liquid flow rate and air speed and volume; thus, actual droplet size distributions cannot be measured with currently available droplet sizing systems under field conditions. There are 14 total nozzles, seven on each side of the sprayer. There are two spray heads on each side; the top spray head consists of two nozzles that discharge declining spray clouds, while the bottom head consists of five nozzles that discharge spray clouds radially upward.

The retrofit kit of the intelligent spray control system (Shen et al., 2017) is currently the most advanced spray technology and consists of an embedded computer with touch screen, a manual switch box, a high-speed scanning laser rangefinder sensor (UTM30LX; Hokuyo Automatic Co., Ltd., Osaka, Japan), a non-contact Doppler-radar ground travel speed sensor (RVSIII radar velocity sensor; Dickey-John Corp., Auburn, IL), an automatic flow control box, and 14 pulse width modulated (PWM) solenoid valves (55295-1-12; Teejet, Glendale Heights, IL). The retrofit kits can be outfitted on a range of existing sprayers and allow the sprayer to be equipped with this intelligent spray technology without altering their physical dimensions, thereby maintaining compatibility with the crop and field spacing.

The embedded computer and touch screen perform communications between the operator and the sprayer and execute computer programs to control the sprayer operation. The laser sensor was installed on the centerline of a metal frame $1.85 \mathrm{~m}$ above the ground (Fig. 1) and can be used to control spray outputs of individual nozzles independently (Chen et al., 2012). During spray applications, each nozzle activation is manipulated by tree presence, size, shape, and foliage density in real time. Each nozzle is coupled with a PWM solenoid valve installed about $20 \mathrm{~cm}$ upstream of the nozzle (Fig. 2). The spray output of each nozzle is determined by the spray rate, tree volume, and the sprayer travel speed; because characteristics differ from tree to tree, the total spray output per tree will vary. The spray rate is a specific spray volume required for covering a unit of crop volume (e.g., $0.03 \mathrm{~L}$ of spray volume per cubic meter of crop volume) and is selected by the pesticide applicator using the touch screen computer. Detailed information on design and functions of the intelligent spray control system is given by Shen et al. (2017).

For this experiment, the tractor was driven at $4.7 \mathrm{~km} \cdot \mathrm{h}^{-1}$, and the sprayer was operated at $240 \mathrm{kPa}$. The maximum flow rate of each nozzle was $0.70 \mathrm{~L} \cdot \mathrm{min}^{-1}$; that is, the sprayer performed the variable rates with the total spray output ranging from 0 to $9.80 \mathrm{~L} \cdot \mathrm{min}^{-1}$ during spray applications.

The default spray rate for the intelligent spray system is $0.07 \mathrm{~L} \cdot \mathrm{m}^{-3}$; and in preliminary tests, this was compared with the grower's standard volume per hectare application of $1540 \mathrm{~L} \cdot \mathrm{ha}^{-1}$, which was approximated as 0.11 $\mathrm{L} \cdot \mathrm{m}^{-3}$ based on visual comparison of the spray output. Following these preliminary tests, three additional rates $(0.03,0.05$, and 0.09 $\mathrm{L} \cdot \mathrm{m}^{-3}$ ) were selected that would test a reasonable range and could potentially identify lower rates that would still meet spray application guidelines.

Uniform Malus domestica 'Golden Delicious' apple trees on M-26 full-dwarfing rootstock planted in $2011 \approx 1.5 \mathrm{~m}$ apart in two $\approx 120$-m long rows running in an east-west orientation located at Oren Wooden's Apple

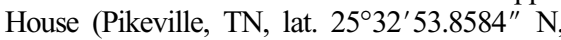
long. $85^{\circ} 9^{\prime} 10.1304^{\prime \prime}$ W) were used for this study (Fig. 3). On 28 Sept. 2017 and 4 Oct. 2018 , four pairs of trees across the driveway from one another were selected, with heights ranging from 290 to $440 \mathrm{~cm}$, widths parallel to the row ranging from 255 to $455 \mathrm{~cm}$, and widths perpendicular to the row ranging from 295 to $440 \mathrm{~cm}$. Four clips for $5.08-\times 7.62-\mathrm{cm}$ water-sensitive cards (WSCs) (Syngenta Crop Protection AG, Basel, Switzerland) were placed equidistant from one another within each canopy at a height of 170 to 180 $\mathrm{cm}$. In 2018 only, a fifth WSC was clipped to a board and placed on the ground below WSC position 2 to capture off-target loss to the orchard floor (Fig. 4). WSCs change color from yellow to dark blue when they become wet, and they are widely used to measure foliar spray characteristics under field conditions (Ozlüoymak and Bolat, 2020; Zhu et al., 2011a).

One of four spray rates, 0.03, 0.05, 0.07, or $0.09 \mathrm{~L} \cdot \mathrm{m}^{-3}$, was randomly assigned to each pair of trees within the row so that all four rates were tested on each of four runs. WSCs were placed in the clips, and the trees were sprayed with water using the radial airassisted sprayer retrofitted with the laserguided intelligent spray control system (Shen et al., 2017) operated in the automatic 


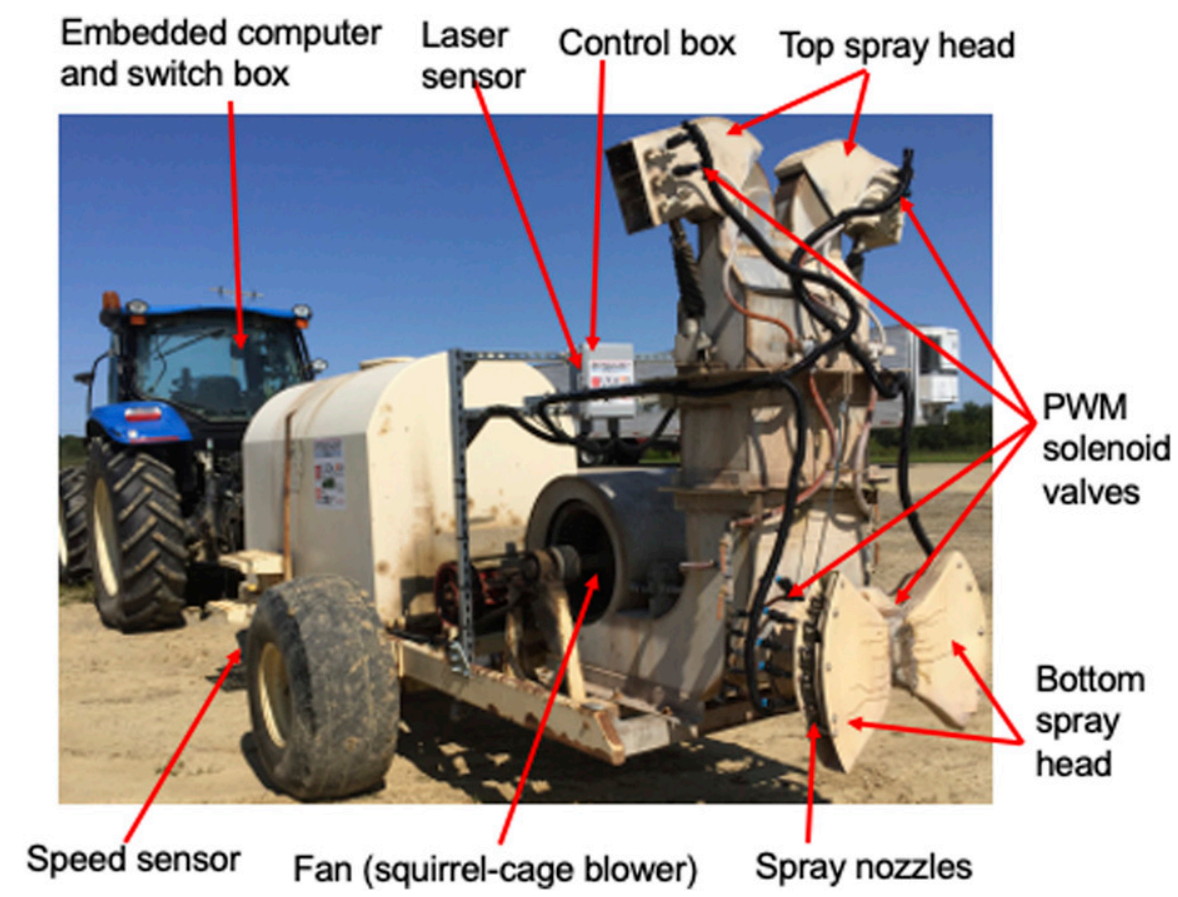

Fig. 1. Air-assisted sprayer (AgTec CS-1000; Superb Horticulture, Plymouth, IN) retrofitted with intelligent sprayer system.

variable-rate mode. For the purposes of this experiment, the sprayer was only operated down a single driveway between the pairs of trees; it was not operated on the adjacent driveways. WSCs were collected, rates were randomly re-assigned to tree pairs, and a new WSC was placed in each clip before each of the three subsequent runs.

WSCs were collected in labeled envelopes, stored briefly with dessicant, and then scanned at 600 dpi (HP Photosmart Plus Allin-One Printer - B209; Hewlett-Packard, Palo Alto, CA). Scanned WSC images were saved as jpg files and were analyzed with the DepositScan program (Zhu et al., 2011a) to obtain spray coverage $(\%)$, deposits $\left(\mu \mathrm{L} \cdot \mathrm{cm}^{-2}\right)$, and deposit density (droplets $/ \mathrm{cm}^{2}$ ).

In 2018 only, after all WSCs were collected, the sprayer was driven down the same driveway at each rate for the full length of the row, in the same order as when using the WSCs, and the volume of spray discharged was recorded from the touch screen monitor connected to the intelligent sprayer system. Each rate was repeated for a total of three replications. A weather station, consisting of an air temperature and relative humidity sensor (HMP60-10-PT; Vaisala Corp., Helsinki, Finland) - connected to a data logger (CR1000; Campbell Scientific, Logan, UT) and powered by a solar panel-was positioned at the end of the block of trees in which testing occurred. Wind speeds were measured using a hand-held anemometer (Kestrel 3000; Nielsen-Kellerman Company, Boothwyn, PA). During testing, the air temperature was 26.2 to $26.8{ }^{\circ} \mathrm{C}$, relative humidity was $62.5 \%$ to $67.6 \%$, average wind speed was $0.65 \mathrm{~m} \cdot \mathrm{s}^{-1}$, and the $\max$ wind speed was $2.1 \mathrm{~m} \cdot \mathrm{s}^{-1}$. The application rate for the tree row volume method was calculated for comparison purposes as follows (Zhu et al., 2008):

$$
V=\frac{1000 \times D \times H}{S}
$$

where $V$ is the spray application rate $\left(\mathrm{L} \cdot \mathrm{ha}^{-1}\right)$; $D$ is the tree width $(\mathrm{m}) ; H$ is the tree height (m); and $S$ is the distance between rows $(\mathrm{m})$.

Any coverage value greater than $30 \%$ was defined as overspray. This threshold was defined by Zhu et al. (2008) and indicated that cards with greater than $30 \%$ spray coverage received more than sufficient application for effective pest control.

The overspray index was calculated as follows (Chen et al., 2013a):

$$
I_{O}=\frac{C-30}{100-30},
$$

where $I_{O}$ is the overspray index and $C$ is the spray coverage on WSC $(\%)$.

The overspray calculation was made using data from all cards regardless of coverage percentage so that overspray, as well as the degree to which cards were not oversprayed, could be determined.

The effects of spray rate, WSC position, and their interaction on deposit density, deposits, and coverage were analyzed using a mixed model analysis for split-plot design. The whole plot was the tree direction (north or south side of the driveway), and the split plot was the spray rate. Each pair of trees was a block. There were eight replicate trees and four runs for WSC-generated data, and three replicates for pesticide volume discharged. There was no effect of year, so data were pooled. Diagnostic analysis was conducted to
Spray nozzles with speciallydesigned 2-hole air-shear tips

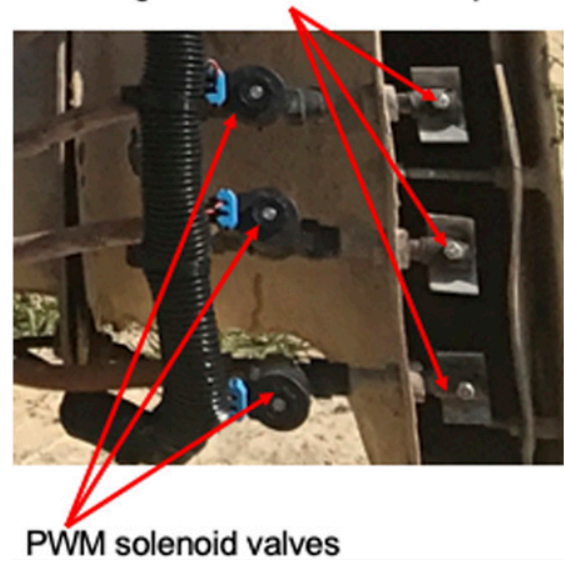

Fig. 2. Pulse width modulated (PWM) solenoid valves installed upstream from the spray nozzles to discharge variable-rate sprays.

examine model assumptions. Ranked transformation was applied if diagnostic analysis exhibited violation of normality and equal variance assumptions. Post hoc multiple comparisons were performed with Tukey's adjustment. Statistical significance was identified at the level of 0.05 . Analyses were conducted in SAS 9.4 TS1M4 for Windows 64x (SAS Institute Inc., Cary, NC).

\section{Results and Discussion}

Spray volume was strongly correlated with spray rate $\left(r^{2}=0.99\right)$ and increased linearly as the spray rate increased. The application rate ranged from $262 \mathrm{~L} \cdot \mathrm{ha}^{-1}$ when the spray rate was $0.03 \mathrm{~L} \cdot \mathrm{m}^{-3}$ to $638 \mathrm{~L} \cdot \mathrm{ha}^{-1}$ when the rate was $0.09 \mathrm{~L} \cdot \mathrm{m}^{-3}$. Thus, the application rate increased 2.4 times, while the spray rate increased 3 times. The reason for this difference is that the intelligent spray system controls individual nozzle flow rates with duty cycles of PWM solenoid valves attached to their corresponding nozzles to match sectional canopy foliage volume. To prevent trees from being undersprayed, the computer program in the sprayer assigns duty cycles as $20 \%$ when any duty cycles are below 20\% (Chen et al., 2012). When spraying the same trees, the chance of duty cycles below $20 \%$ is greater with lower rates than that with higher rates; thus producing a higher ratio of spray volume to the spray rate for the trees at lower rates.

On target cards, coverage ranged from $18.5 \%$ to $68.4 \%$ and $23.5 \%$ to $78.3 \%$ from the 0.05 and $0.07 \mathrm{~L} \cdot \mathrm{m}^{-3}$ rates, respectively (Table 1). Similarly, Chen et al. (2013a) used a prototype of this intelligent spray system at a spray rate of $0.06 \mathrm{~L} \cdot \mathrm{m}^{-3}$ and had coverage that ranged from $22 \%$ to $58 \%$ at full foliage.

Coverage $(\%)$ did not have a spray rate $x$ WSC position interaction $(P=0.0950$; Table 1$)$. Coverage was affected by spray rate $(P<0.0001)$ and WSC position $(P<0.0001)$. As 

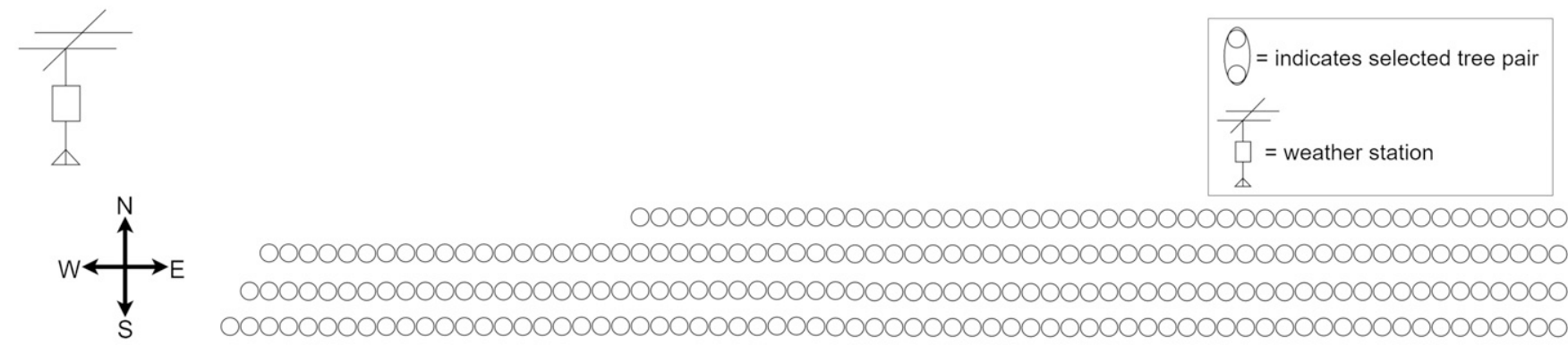

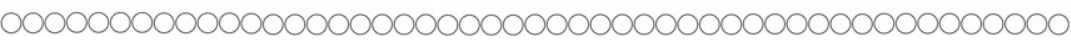

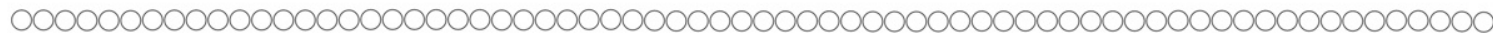

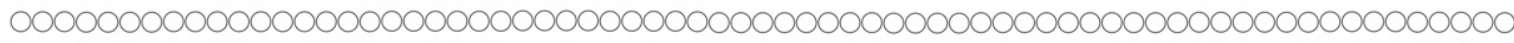

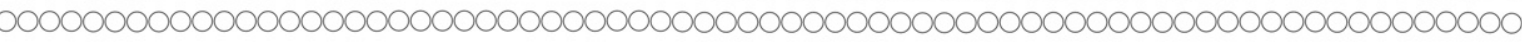
, 000000000000000000000000000000000000000000000000000000000000000000000 ○, 000000000000000000000000000000000000000000000000000000000000000000000

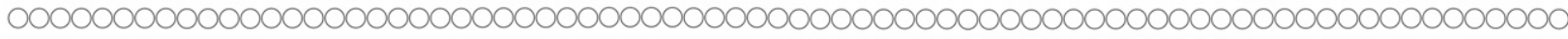

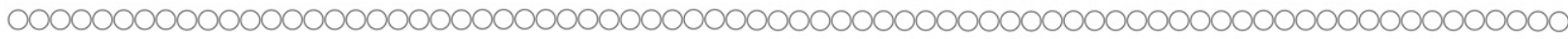

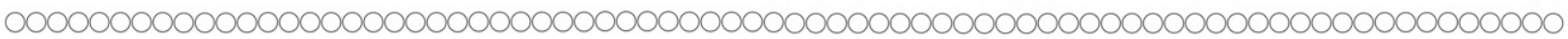

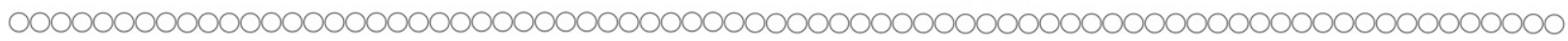

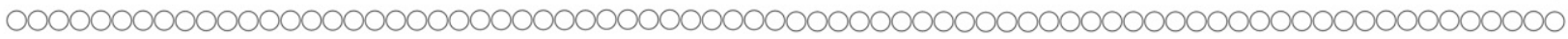

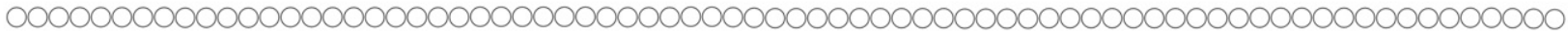
$\stackrel{00000000000000000090000000000009000000000000000090000000000000000000000000}{\longrightarrow}$ ๑0000000000000000000000000000000000000000000000000000000000000000000000000

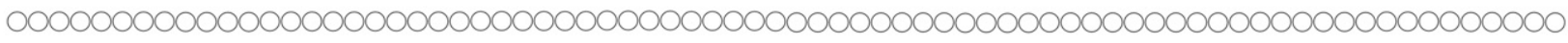

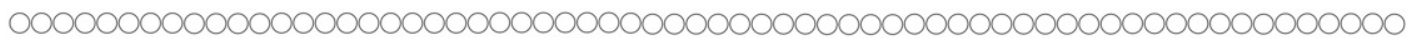

Fig. 3. Plot diagram showing the cardinal direction, orientation of weather station to the field, and rows of trees used in this study. Individual trees are denoted by open circles.
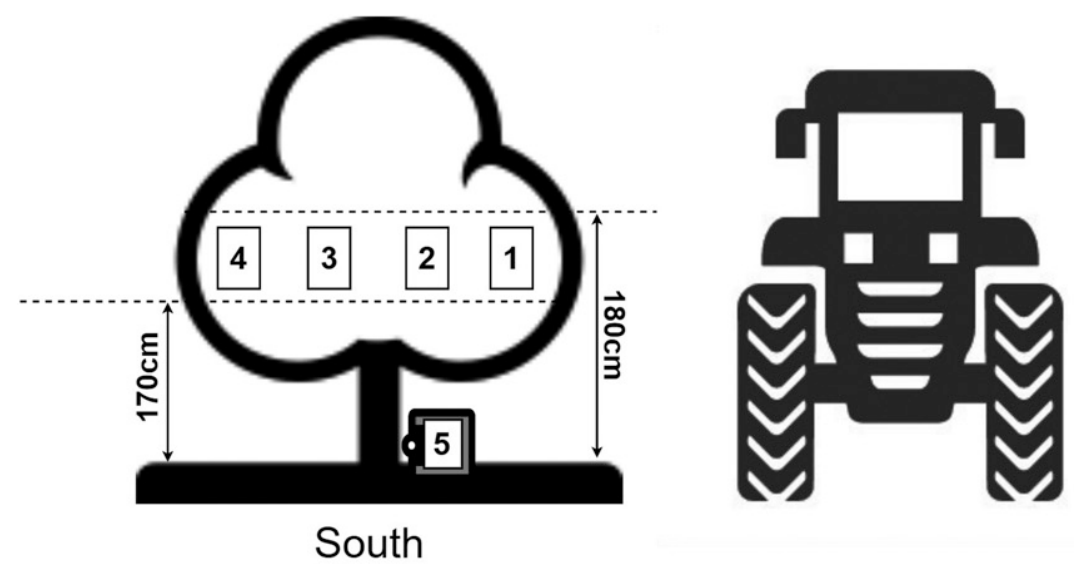

Fig. 4. Tree direction (South and North) and card position (1-5) shown in a pair of trees across the driveway from one another. the rate increased, coverage also increased. For target spray application represented by WSC positions $1,2,3$, and 4 , coverage increased $73.2 \%, 105 \%, 123 \%$, and $239 \%$, respectively, for applications made at the highest rate $\left(0.09 \mathrm{~L} \cdot \mathrm{m}^{-3}\right)$ compared with the lowest rate $\left(0.03 \mathrm{~L} \cdot \mathrm{m}^{-3}\right)$. Even with the tree canopy largely shielding the WSC in position 5 , the highest rate had over five times more coverage than the lowest rate, indicating rate can tremendously influence off-target loss to the ground and underscoring the need to improve and refine rates used in tree crops. Coverage decreased with increasing distance from the sprayer. For each rate, WSC positions 1 and 2 had greater coverage than position 3 , which had greater coverage than positions 4 and 5 . Further, at the highest rate, WSC position 1 had $84.7 \%$ coverage, while WSCs in position 4 had less than half that coverage. At the lowest rate, coverage decreased by $79.3 \%$ between WSC positions 1 and 4, to just $10.1 \%$ coverage for WSC position 4 . For conventional air-assisted sprayers, increasing application rate increases spray volume and overall coverage, but it does not greatly increase spray coverage inside tree canopies (Zhu et al., 2008). For the retrofitted intelligent sprayer in the present study, not only did increasing the application rate increase spray volume, but coverage also increased with increasing spray rate at each WSC position (Table 1). These results demonstrate that the sensing and variable rate application technology is adjusting the spray output based on crop volume and that the targeted spray is penetrating the canopy.

For coverage, the coefficient of variation (CV) increased as distance from the sprayer increased for all rates, indicating that the most uniform coverage occurs closest to the sprayer where coverage tended to be the greatest. CV tended to be high for position 5, which likely is due to differences in canopy structure, for example whether there was a branch directly above the WSC or not.

Spray rate $(P<0.0001)$ and WSC position $(P<0.0001)$ affected overspray index. However, there was also a spray rate $\times$ WSC position interaction ( $P=0.0028$; Fig. 5). WSC positions 1 and 2 had greater overspray than WSC position 4, except WSC position 2 at the $0.03 \mathrm{~L} \cdot \mathrm{m}^{-3}$ rate, which was not different from WSC position 4 sprayed at the 0.09 $\mathrm{L} \cdot \mathrm{m}^{-3}$ rate. Generally, as spray rate increased, overspray index increased-and as distance between WSC and the sprayer increased, overspray index decreased. On average, overspray index was $\approx 15,30$, and 40 times greater at the $0.05,0.07$, and $0.09 \mathrm{~L} \cdot \mathrm{m}^{-3}$ rates, respectively, than the lowest rate $\left(0.03 \mathrm{~L} \cdot \mathrm{m}^{-3}\right)$. Average overspray index was $0.60,0.39,0.19$, and -0.12 at WSC positions 
Table 1. Coverage and deposition as indicated by four water-sensitive card positions placed within the canopy of Malus domestica 'Golden Delicious' and one nontarget ground card sprayed with four rates by a laser-guided sprayer. Coefficient of variation is in parentheses.

\begin{tabular}{|c|c|c|c|c|c|}
\hline & & \multicolumn{4}{|c|}{ Rate $\left(\mathrm{L} \cdot \mathrm{m}^{-3}\right)$} \\
\hline & & 0.03 & 0.05 & 0.07 & 0.09 \\
\hline Card position & & \multicolumn{4}{|c|}{ Coverage $(\%)$} \\
\hline 1 & & $\begin{array}{l}48.9 \mathrm{de}^{\mathrm{z}} \\
(22.7)\end{array}$ & $\begin{array}{l}68.4 \mathrm{bc} \\
(22.8)\end{array}$ & $\begin{array}{l}78.3 \mathrm{ab} \\
(20.9)\end{array}$ & $\begin{array}{l}84.7 \mathrm{a} \\
(23.6)\end{array}$ \\
\hline 2 & & $\begin{array}{l}38.1 \mathrm{f} \\
(32.4)\end{array}$ & $\begin{array}{l}48.1 \mathrm{e} \\
(32.7)\end{array}$ & $\begin{array}{l}67.8 \mathrm{bc} \\
(29.8)\end{array}$ & $\begin{array}{l}78.1 \mathrm{ab} \\
(20.2)\end{array}$ \\
\hline 3 & & $\begin{array}{l}27.1 \mathrm{gh} \\
(49.1)\end{array}$ & $\begin{array}{l}36.5 \mathrm{f} \\
(46.2)\end{array}$ & $\begin{array}{l}52.2 \mathrm{de} \\
(31.2)\end{array}$ & $\begin{array}{l}60.3 \mathrm{~cd} \\
(33.3)\end{array}$ \\
\hline 4 & & $\begin{array}{l}10.1 \mathrm{jk} \\
(57.9)\end{array}$ & $\begin{array}{l}18.5 \mathrm{hi} \\
(68.5)\end{array}$ & $\begin{array}{l}23.5 \mathrm{hi} \\
(52.4)\end{array}$ & $\begin{array}{l}34.2 \mathrm{fg} \\
(45.3)\end{array}$ \\
\hline 5 & & $\begin{array}{l}4.7 \mathrm{k} \\
(53.4)\end{array}$ & $\begin{array}{l}6.4 \mathrm{jk} \\
(40.5)\end{array}$ & $\begin{array}{l}17.3 \mathrm{ij} \\
(65.5)\end{array}$ & $\begin{array}{l}24.8 \text { ghi } \\
(44.9)\end{array}$ \\
\hline \multicolumn{6}{|l|}{$P$ values } \\
\hline Spray rate & $<0.0001$ & & & & \\
\hline Card position & $<0.0001$ & & & & \\
\hline Spray rate $\times$ card position & 0.0950 & & & & \\
\hline Card position & & \multicolumn{4}{|c|}{ Deposits $\left(\mu \mathrm{L} \cdot \mathrm{cm}^{-2}\right)$} \\
\hline 1 & & $\begin{array}{c}25.5 \text { e } \\
(136.4)\end{array}$ & $\begin{array}{l}97.0 \mathrm{~cd} \\
(57.4)\end{array}$ & $\begin{array}{l}128.3 \mathrm{ab} \\
(45.7)\end{array}$ & $\begin{array}{l}148.3 \mathrm{a} \\
(46.4)\end{array}$ \\
\hline 2 & & $\begin{array}{c}11.0 \mathrm{fg} \\
(197.1)\end{array}$ & $\begin{array}{c}33.0 \mathrm{e} \\
(126.9)\end{array}$ & $\begin{array}{l}92.0 \mathrm{bcd} \\
(72.4)\end{array}$ & $\begin{array}{l}120.7 \mathrm{abc} \\
(53.8)\end{array}$ \\
\hline 3 & & $\begin{array}{l}3.0 \mathrm{hi} \\
(85.9)\end{array}$ & $\begin{array}{l}11.5 \mathrm{f} \\
(143.6)\end{array}$ & $\begin{array}{c}41.3 \mathrm{e} \\
(118.3)\end{array}$ & $\begin{array}{l}59.2 \text { de } \\
(106.4)\end{array}$ \\
\hline 4 & & $\begin{array}{l}0.6 \mathrm{jk} \\
(76.8)\end{array}$ & $\begin{array}{c}1.8 \mathrm{ij} \\
(108.9)\end{array}$ & $\begin{array}{c}2.4 \mathrm{i} \\
(70.7)\end{array}$ & $\begin{array}{l}9.0 \mathrm{fgh} \\
(146.3)\end{array}$ \\
\hline 5 & & $\begin{array}{c}0.2 \mathrm{k} \\
(68.8)\end{array}$ & $\begin{array}{l}0.3 \mathrm{jk} \\
(43.8)\end{array}$ & $\begin{array}{c}1.7 \mathrm{ij} \\
(114.2)\end{array}$ & $\begin{array}{l}3.8 \mathrm{ghi} \\
(155.3)\end{array}$ \\
\hline$P$ values & & & & & \\
\hline Spray rate & $<0.0001$ & & & & \\
\hline Card position & $<0.0001$ & & & & \\
\hline Spray rate $\times$ card position & 0.0889 & & & & \\
\hline
\end{tabular}

${ }^{\mathrm{z}}$ Means followed by the same letter are not significantly different, $\alpha=0.05$.

$\mathrm{n}=288 ; \mathrm{n}$ is the total number of cards analyzed.

1, 2, 3, and 4, respectively; WSC positions 1 and 2 were oversprayed at all rates. At WSC position 3 , the overspray index was negative only for the lowest rate $\left(0.03 \mathrm{~L} \cdot \mathrm{m}^{-3}\right)$, indicating that it was oversprayed at the other, higher rates. The overspray index for WSC position 4 was negative for all but the highest rate $\left(0.09 \mathrm{~L} \cdot \mathrm{m}^{-3}\right)$, indicating that cards in this location of the canopy were only oversprayed when the highest rate was used.

As with coverage, the magnitude of the $\mathrm{CV}$ for overspray index increased as the distance from the sprayer increased for all rates, except WSC position 4 at the lowest rate $\left(0.03 \mathrm{~L} \cdot \mathrm{m}^{-3}\right)$. As rate increased, the magnitude of the $\mathrm{CV}$ for overspray index decreased at WSC positions 1 through 3 but increased at WSC position 4.

Deposits $\left(\mu \mathrm{L} \cdot \mathrm{cm}^{-2}\right)$ did not have a rate $X$ WSC position interaction $(P=0.0889$; Table 1). Like coverage, deposits were affected by spray rate $(P<0.0001)$ and WSC position $(P<0.0001)$. Deposits increased as spray rate increased but were negatively affected by distance from the sprayer. For WSC position 4 (the target WSC position most distal to the sprayer), spray deposits were 15 times and 5 times greater for the highest rate compared with the 0.03 and $0.05 \mathrm{~L} \cdot \mathrm{m}^{-3}$ rates, respectively. More deposits at higher spray rates are achieved because higher spray rates produce greater deposit density, which creates better spray penetration in canopies than the lower rates. However, deposits increased disproportionately with increasing rate, as the high- est rate was only 2.0 times and 0.80 times greater than the 0.03 and $0.05 \mathrm{~L} \cdot \mathrm{m}^{-3}$ rates, respectively. Even for WSC position 1 (the target WSC most proximal to the sprayer), the highest rate had deposits that were nearly 5-fold greater than the lowest rate. While deposits were low overall for WSC position 5 (the nontarget ground), they were 19 times greater for the highest rate compared with the lowest rate. At all spray rates, deposits were greater for WSC positions 1, 2, and 3 than for WSC positions 4 and 5.

Similarly, the increase in deposits with increasing rate indicates that the sprayer is detecting the crop and discharging sprays based on tree characteristics and the assigned spray rate. Previously, to optimize deposition within the canopy, trees had to be pruned and thinned accordingly (Travis et al., 1987a); nozzle orifice sizes had to be assigned to specific nozzle positions based on tree size to disproportionately target the upper $1 / 3$ of the canopy (Travis et al., 1987b); or a second set of nozzles with a different application rate had to be manually selected. With this spray technology, however, the appropriate amount of pesticide can be applied automatically based on tree sectional volume profiles without increasing production tasks or applicator exposure.

At the $0.05 \mathrm{~L} \cdot \mathrm{m}^{-3}$ rate, which applied 381 $\mathrm{L} \cdot \mathrm{ha}^{-1}$, the deposit density of WSCs in positions 1 through 4 ranged from 52.8 to 158.4 droplets $/ \mathrm{cm}^{2}$ (Fig. 6). These results are similar to the study of Jamar et al. (2010), which found that at a height from 1.8 to $2 \mathrm{~m}$, deposit density ranged from 69 to 227 droplets $/ \mathrm{cm}^{2}$ when using two different sprayers with two types of nozzles calibrated to apply 350 $\mathrm{L} \cdot \mathrm{ha}^{-1}$ to dwarf apple trees.

For deposit density (droplets $\left./ \mathrm{cm}^{2}\right)$ there was a rate $\times$ WSC position interaction $(P<$ 0.0001; Fig. 6). The main effects were significant: spray rate $(P=0.0020)$ and WSC position $(P<0.0001)$. Deposit density was greater for the lowest rate than the two highest rates in WSCs in positions 1, 2, and 3 . However, for the most distal target WSC in position 4 and the off-target ground WSC in position 5 , the two highest rates had a greater deposit density than the lowest spray rate. When coverage is greater than $30 \%$, as for WSCs in positions 1 through 3, and sprayed at either of the highest two rates, deposit density is artificially low due to individual droplets coalescing, which explains the interaction. After accounting for these artificially low values, at each rate the deposit densities on all target WSCs (positions 1 through 4) met or exceeded the recommended thresholds for both insecticides, 20-30 droplets $/ \mathrm{cm}^{2}$, and fungicides, 50-70 droplets $/ \mathrm{cm}^{2}$ (Berni et al., 1999; Penido et al., 2019; Syngenta AG, 2002). However, these deposit density guidelines are general recommendations, and spray operators may want to make adjustments, particularly by taking droplet size and coverage into consideration and by setting a higher threshold for contact pesticides.

$\mathrm{CV}$ for deposit density generally increased with increasing spray rate. For WSC 1 , this was particularly pronounced with a 1.7 -fold, 2.2-fold, and 3.7-fold increase in variation between the lowest $\left(0.03 \mathrm{~L} \cdot \mathrm{m}^{-3}\right)$ rate and the $0.05,0.07$, and $0.09 \mathrm{~L} \cdot \mathrm{m}^{-3}$ rates, respectively.

WSCs are useful for characterizing spray deposition patterns, in part because their relative affordability allows sufficient replication, but they also have limitations. While coverage data from WSCs is widely accepted, deposit density data are affected by the fact that the DepositScan program cannot differentiate overlapping deposits as individual droplets, and deposit data are hindered by the same issue ( $\mathrm{Zhu}$ et al., 2011a). Witton et al. (2018) combined conventional residue analysis with the use of WSCs in an apple orchard and compared the two. They found that for WSCs with coverage less than $30 \%$, the calculated deposits were strongly correlated with the mass-based leaf residue value. They concluded that WSCs may be a viable alternative for low-cost, highthroughput assessment of spray deposits, but that residue analysis is likely necessary to determine a correction factor for individual scenarios (e.g., different tracers used for deposition, chemical concentrations, wetting agents, etc.). However, they also found that WSCs consistently overestimate trends within tree differences; therefore, while the deposits may not reflect absolute values in the present study, the trend they represent is accurate. 


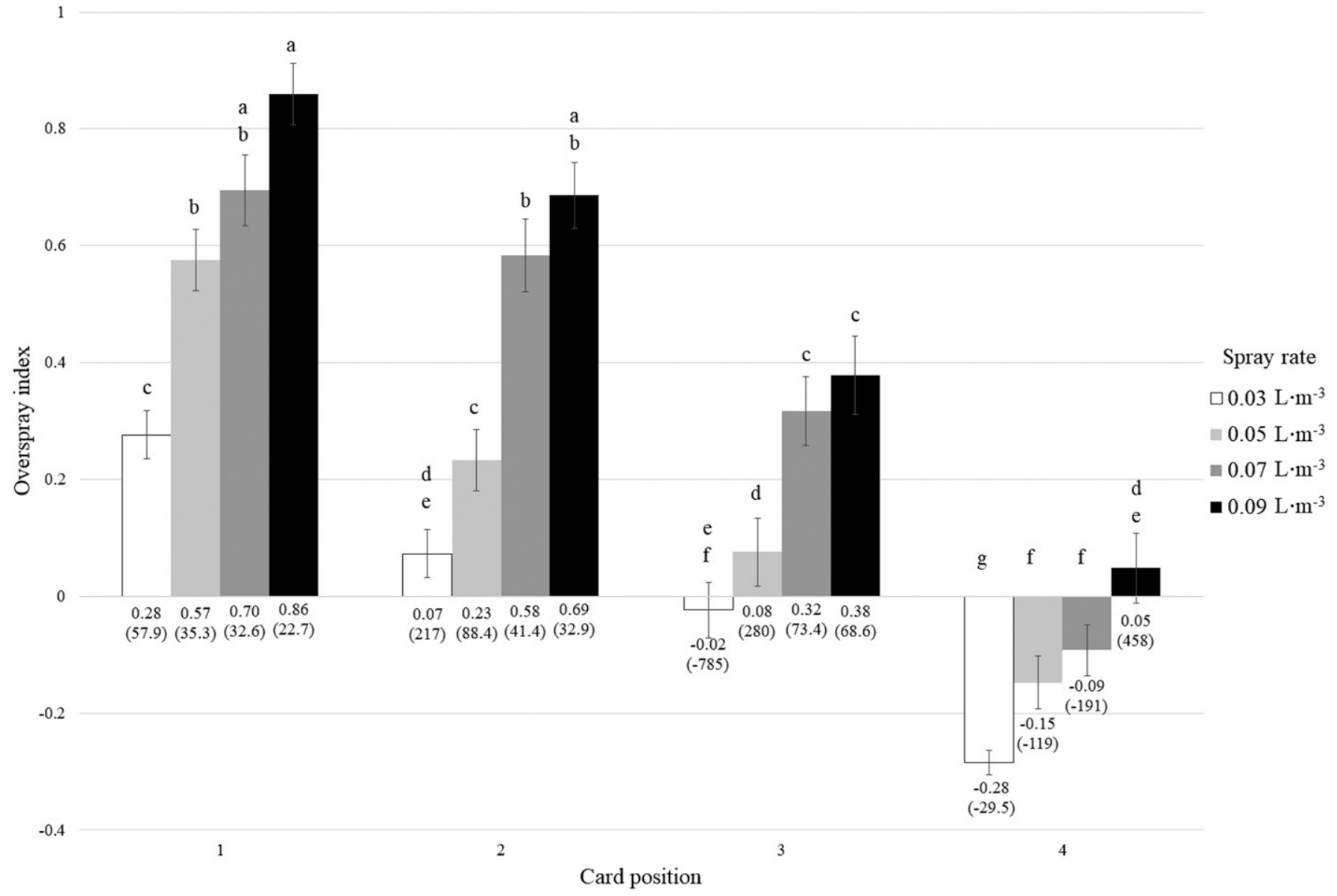

Fig. 5. Mean overspray index in Malus domestica 'Golden Delicious' sprayed at four rates by a laser-guided sprayer ( $\mathrm{n}=288$ ). Bars associated with the same letters are not significantly different, $\alpha=0.05$. SE is shown graphically via error bars, CV is shown in parentheses.

In this study, trees were sprayed as the tractor traveled in one direction down a single driveway. In practice, however, orchard and nursery operators would typically spray down each driveway. Consequently, actual spray deposits on each WSC would likely be much greater following a standard pesticide application. Additionally, the opposite side of each WSC would have spray deposits similar to that of the target WSC on the other side of the canopy in the corresponding position (i.e., a WSC positioned back-to-back with the WSC in position 4 sprayed from the adjacent driveway would have spray deposits similar to that of WSC position 1). Therefore, an application at any of the tested rates would overapply the pesticide. When applied from a single pass, the lowest rate in this study, 0.03 $\mathrm{L} \cdot \mathrm{m}^{-3}$, met published deposit density guidelines (Berni et al., 1999; Penido et al., 2019; Syngenta AG, 2002), and 93\% of WSCs in positions 1 through 4 at this rate had either greater than $15 \%$ coverage or greater than 70 droplets $/ \mathrm{cm}^{2}$ (data not shown). This is an even higher proportion than that found in a study by Chen et al. (2012) that concluded that the intelligent sprayer was able to provide sufficient spray coverage. This suggests that the potential exists to further reduce spray rates, but this possibility requires additional research that more fully characterizes spray within the entire canopy by including WSCs placed at higher and lower positions in the canopy to compliment the WSCs placed transversely. It is also possible that spray rate could be further modulated depending on crop phenological stage to achieve pest control while minimizing pesticide volume. These 'Golden Delicious' trees had dense foliage at the time of the experiment and yet even at the lowest rate $\left(0.03 \mathrm{~L} \cdot \mathrm{m}^{-3}\right)$ WSCs in positions 1 and 2 were oversprayed. In the spring, an even lower rate would likely provide the suggested deposit density range.

Producers of all tree crops have the potential to benefit from this new laser-guided variable-rate technology. Ornamental nursery operators face several of the same challenges to spray application efficiency that orchardists do, plus the added challenges of crop heterogeneity due to the hundreds of species of plants grown (Yeager et al., 2013) and greater spacing between crops causing more canopy gaps within a row (Zhu et al., 2006, 2008). Nursery producers often adopt constant-rate spray systems, consisting of airassisted sprayers from other, larger tree crops, further contributing to low spray application efficiency (Zhu et al., 2017). In preliminary experiments, using this technology to spray a multirow block of full-foliaged Shumard oaks (Quercus shumardii L.) re- duced the pesticide volume discharged by $30 \%$ compared with a constant rate of 480 $\mathrm{L} \cdot \mathrm{ha}^{-1}$, which is considered a half rate compared with the typical $935 \mathrm{~L} \cdot \mathrm{ha}^{-1}$ applied at nurseries (Fessler et al., 2019; Zhu et al., $2011 \mathrm{~b}$ ). The average volume of a Shumard oak tree in this nursery was $3.9 \mathrm{~m}^{3}$, compared with $42.0 \mathrm{~m}^{3}$ for the 'Golden Delicious' apple trees in this study. The size difference coupled with success achieving recommended deposit density ranges suggest that further reductions in spray rate using this laserguided technology may have the potential to dramatically reduce spray volume and offtarget losses in nurseries and in other woody crops.

Applying a spray solution at the lowest rate of $0.03 \mathrm{~L} \cdot \mathrm{m}^{-3}$ with a variable-rate laserguided sprayer exceeded deposit density efficacy levels and would reduce spray volume by $83 \%$ (compared with the grower's standard constant rate application) and by $87 \%$ (compared with using the tree row volume method), 1540 and $1950 \mathrm{~L} \cdot \mathrm{ha}^{-1}$, respectively, for this plot. The potential to reduce offtarget application is particularly notable at the orchard floor. In other studies, coverage on the ground was less than half in the variable-rate mode compared with using the sprayer in the constant-rate mode when operated at $0.09 \mathrm{~L} \cdot \mathrm{m}^{-3}$ rate (Fulcher, 


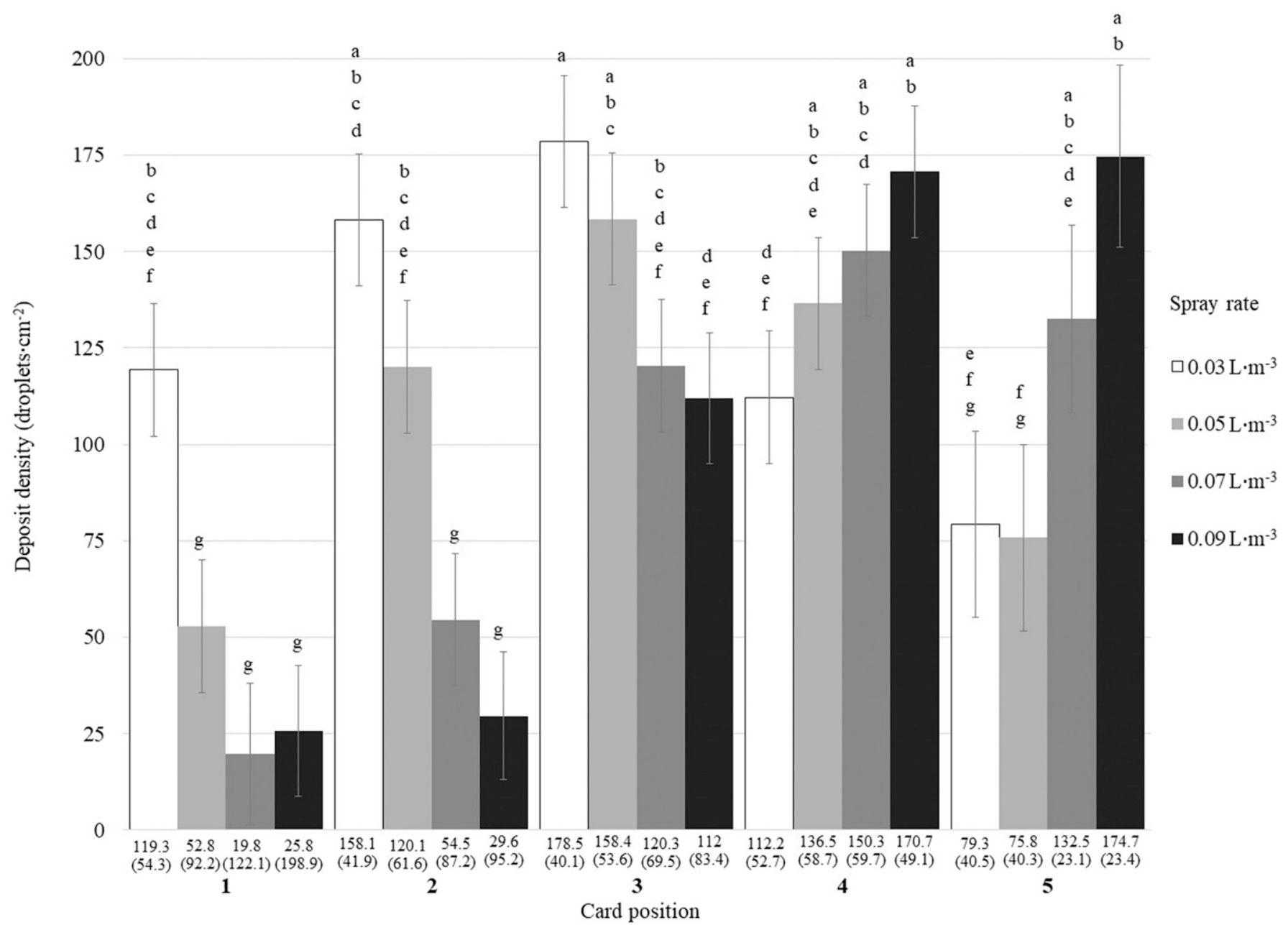

Fig. 6. Mean deposit density in Malus domestica 'Golden Delicious' sprayed at four rates by a laser-guided sprayer $(\mathrm{n}=288)$. Bars associated with the same letters are not significantly different, $\alpha=0.05$. SE is shown graphically via error bars, $\mathrm{CV}$ is shown in parentheses.

unpublished data). At the highest tested rate of $0.09 \mathrm{~L} \cdot \mathrm{m}^{-3}$, the total spray volume would still be reduced by $59 \%$ compared with the grower's standard constant rate application.

Because this technology can greatly reduce total spray volume, some growers may be concerned about reduced efficacy of applied products. However, a study conducted at two nurseries on a variety of crops using identical intelligent spray technology, in which spray volume was reduced by more than $50 \%$ compared with the conventional spray mode, concluded that this variable-rate technology effectively controlled each of the four pests that were scouted (Chen et al., 2019). A comparable study was conducted on apple (Malus pumila Mill.), peach [Prunus persica (L.) Batsch], blueberry (Vaccinium sect. Cyanococcus Rydb.), and black raspberry (Rubus occidentalis L.) using the prototype of this intelligent spray technology (Chen et al., 2020). In this study, the intelligent sprayer reduced spray volume $\approx 50 \%$ and achieved similar control of a range of insects and diseases as the conventional sprayer. Additionally, Zhu et al. (2011b) demonstrated that applying pesticides with a conventional airblast sprayer at $50 \%$ of the labeled volume application rate, $\approx 470 \mathrm{~L}$ of spray solution per hectare, provided insect and disease control that was as effective as the full rate, $940 \mathrm{~L}$ per hectare.

In a single year, U.S. agriculture consumes a total of 398 million $\mathrm{kg}$ of pesticides (Pimentel and Burgess, 2014). Apple production alone in the United States consumes $\approx 8$ million $\mathrm{kg}$ of fungicides and 1.5 million $\mathrm{kg}$ of insecticides annually (USDA, 2018). If this intelligent sprayer technology was widely adopted in apple orchards, even at the highest spray application rate tested, $\approx 4$ million less kilograms of pesticide would be applied each year, and apple producers would save millions in pesticide input costs. These estimates are specific to the apple industry; but other cropping systems, such as peach, grape, and citrus, which use 1.1 million, 16 million, and 5 million $\mathrm{kg}$ of insecticides and fungicides, respectively, each year (USDA, 2018), and the nursery industry, which uses 1.3 million $\mathrm{kg}$ of chemical pesticides per year (USDA, 2011), can also use this technology. Besides the economic benefit of adopting intelligent spray technology, growers would also benefit from decreased environmental impact and decreased potential for worker exposure.

\section{Conclusions}

The results of this study highlight the ability of laser rangefinder-based intelligent spray technology to decrease total spray volume output while maintaining adequate coverage and deposit density throughout the canopy, even at low rates. The lowest rate applied, $0.03 \mathrm{~L} \cdot \mathrm{m}^{-3}$, reduced spray volume by $83 \%$ compared with the grower's standard application and exceeded recommended deposit densities even in the portion of the canopy located farthest from the sprayer. The highest rate $\left(0.09 \mathrm{~L} \cdot \mathrm{m}^{-3}\right)$ caused overspray at every WSC position, despite using $59 \%$ less spray volume than the grower's standard application. These results suggest that even lower rates could achieve adequate spray applications, especially to smaller, less dense, or more widely spaced trees. While initial experiments comparing pest control in plots sprayed in constant-rate vs. variablerate have been performed, further research is necessary to more fully investigate a range of 
pest types, as well as pest control levels achieved with the combination of variablerate technology and application rates lower than the default rate. Additionally, further work is necessary to explore how this technology operates in similar cropping systems, such as nurseries. Our study has increased the understanding of how this intelligent spray technology operates on a commercial apple orchard scale; characterized the spray application and volume at a range of rates; and facilitated progress toward defining appropriate rates for pesticide application in apple orchards, which brings us one step closer to providing spray rate guidelines for using this new, commercially available technology to growers and applicators.

\section{Literature Cited}

Berni, R.F., V.D.O.F. Machado, G.R. Costa, G. Barata, and R.S. De Paula. 1999. Avaliação da cobertura de gotas provocada por diferentes bicos de pulverização na cultura do milho e do feijão. Pesqui. Agropecu. Trop. (Agricultural Research in the Tropics) 29:49-52.

Blanco, M.N., R.A. Fenske, E.J. Kasner, M.G. Yost, E. Seto, and E. Austin. 2019. Real-time monitoring of spray drift from three different orchard sprayers. Chemosphere 222:46-55

Buisman, P., K.M. Sundaram, A. Sundaram, and K. Trammel. 1989. Field deposit patterns of a diflubenzuron spray mix, after application to an apple orchard using an air-blast sprayer; and a laboratory evaluation of physical properties and atomization characteristics. J. Environ. Sci. Health B 24(4):389-411.

Chen, L., M. Wallhead, M. Reding, L. Horst, and H. Zhu. 2020. Control of insect pests and diseases in an Ohio fruit farm with a laserguided intelligent sprayer. HortTechnology $1: 1-8$.

Chen, L., M. Wallhead, H. Zhu, and A. Fulcher. 2019. Control of insects and diseases with intelligent variable-rate sprayers in ornamental nurseries. J. Environ. Hort. 37(3):90-100.

Chen, Y., H.E. Ozkan, H. Zhu, R.C. Derksen, and C.R. Krause. 2013a. Spray deposition inside tree canopies from a newly developed variablerate air-assisted sprayer. Trans. ASABE 56(6):12631272.

Chen, Y., H. Zhu, and H. Ozkan. 2012. Development of a variable-rate sprayer with laser scanning sensor to synchronize spray outputs to tree structures. Trans. ASABE 55(3):773781.

Chen, Y., H. Zhu, H.E. Ozkan, R.C. Derksen, and C.R. Krause. 2013b. Spray drift and off-target loss reductions with a precision air-assisted sprayer. Trans. ASABE 56(6):1273-1281.

Cross, J., P. Walklate, R. Murray, and G. Richardson. 2001a. Spray deposits and losses in different sized apple trees from an axial fan orchard sprayer: 1. Effects of spray liquid flow rate. Crop Prot. 20(1):13-30.

Cross, J., P. Walklate, R. Murray, and G. Richardson. 2001b. Spray deposits and losses in different sized apple trees from an axial fan orchard sprayer: 2. Effects of spray quality. Crop Prot. 20(4):333-343.

Damalas, C.A. and I.G. Eleftherohorinos. 2011. Pesticide exposure, safety issues, and risk assessment indicators. Intl. J. Environ. Res. Public Health 8(5):1402-1419.

Darde, D.C., G.K. de Almeida, and G.A.B. Marodin. 2019. Budburst and flowering intensity by the spraying of dormancy-breaking prod- ucts in 'Eva' apple trees. Semin. Cienc. Agrar. 40(3):1049-1062.

Duga, A.T., K. Ruysen, D. Dekeyser, D. Nuyttens, D. Bylemans, B.M. Nicolai, and P. Verboven. 2015. Spray deposition profiles in pome fruit trees: Effects of sprayer design, training system and tree canopy characteristics. Crop Prot. 67:200-213

Fessler, L., A. Fulcher, J. Hines, H. Zhu, T. Hines, W. Wright, W. Yeary, S. Xiaocun, and S. Mcclanahan. 2019. A dynamic laser-guided sprayer reduces pesticide use in large pot-inpot production. HortScience 54:S296-S297 (abstr.).

Fishel, F. M. and T. Sanchez. 2016. [PI263] worker protection standard: Application exclusion zone (AEZ). EDIS 2016(7).

Frank, S., W. Klingeman, III, S. White, and A. Fulcher. 2013. Biology, injury, and management of maple tree pests in nurseries and urban landscapes. J. Integr. Pest Mgt. 4(1):B1-B14.

Grella, M., M. Gallart, P. Marucco, P. Balsari, and E. Gil. 2017. Ground deposition and airborne spray drift assessment in vineyard and orchard: The influence of environmental variables and sprayer settings. Sustainability 9(5):728.

Hočevar, M., B. Sirok, V. Jejčič, T. Godeša, M Lešnika, and D. Stajnko. 2010. Design and testing of an automated system for targeted spraying in orchards. J. Plant Dis. Prot 117(2):71-79.

Hołownicki, R., G. Doruchowski, A. Godyn, and W. Swiechowski. 2000. Effects of air jet adjustment on spray losses in orchard. Asp. Appl. Biol. 57:293-300.

Hołownicki, R., G. Doruchowski, W. Świechowski, A. Godyń, and P.J. Konopacki. 2017. Variable air assistance system for orchard sprayers; concept, design and preliminary testing. Biosyst. Eng. 163:134-149.

Hong, S.-W., L. Zhao, and H. Zhu. 2018. Cfd simulation of pesticide spray from air-assisted sprayers in an apple orchard: Tree deposition and off-target losses. Atmos. Environ. 175:109119.

Jamar, L., O. Mostade, B. Huyghebaert, O. Pigeon, and M. Lateur. 2010. Comparative performance of recycling tunnel and conventional sprayers using standard and drift-mitigating nozzles in dwarf apple orchards. Crop Prot. 29(6):561-566.

Jones, R.K. and D.M. Benson. 2001. Flowering crabapple diseases, p. 157-162. Diseases of woody ornamentals and trees in nurseries. Amer. Phytopathol. Soc. (APS Press), St. Paul, MN.

Kasner, E.J., R.A. Fenske, G.A. Hoheisel, K. Galvin, M.N. Blanco, E.Y. Seto, and M.G. Yost. 2018. Spray drift from a conventional axial fan airblast sprayer in a modern orchard work environment. Ann. Work Expo. Health 62(9):1134-1146.

Kim, K.-H., E. Kabir, and S.A. Jahan. 2017 Exposure to pesticides and the associated human health effects. Sci. Total Environ. 575:525535.

Koleva, N. G., U. A. Schneider, and B. A. McCarl. 2011. Pesticide externalities from the US agricultural sector-The impact of internalization, reduced pesticide application rates, and climate change. Procedia Environ. Sci. 6:153-161.

Lordan, J., P . Vilardell, E . Torres, S . Alegre, and L. Asín. 2019. Use of root pruning, paclobutrazol, and prohexadione-ca combination strategies to control growth and improve productivity on pear trees. Spanish J. Agr. Res. 17(2): e0902.

Nuyttens, D., M. De Schampheleire, K. Baetens, E. Brusselman, D. Dekeyser, and P. Verboven.
2011. Drift from field crop sprayers using an integrated approach: Results of a five-year study. Trans. ASABE 54(2):403-408.

Özlüoymak, Ö.B. and A. Bolat. 2020. Development and assessment of a novel imaging software for optimizing the spray parameters on water-sensitive papers. Comput. Electron. Agr. 168:105104.

Penido, É.D.C.C., M.M. Teixeira, H.C. Fernandes, P.B. Monteiro, and P.R. Cecon 2019. Development and evaluation of a remotely controlled and monitored selfpropelled sprayer in tomato crops. Rev. Cienc. Agron. 50(1):8-17.

Pimentel, D. and M. Burgess. 2014. Integrated pest management and pesticide use, p. 1-46. Integrated pest management. Springer, Boston, MA.

Seagraves, B.L., C.T. Redmond, and D.A. Potter. 2013. Relative resistance or susceptibility of maple (Acer) species, hybrids and cultivars to six arthropod pests of production nurseries. Pest Mgt. Sci. 69(1):112-119.

Shen, Y., H. Zhu, H. Liu, Y. Chen, and E. Ozkan. 2017. Development of a laser-guided, embedded-computer-controlled, air-assisted precision sprayer. Trans. ASABE 60(6):18271838.

Stajnko, D., P. Berk, M. Lešnik, V. Jejčič, M. Lakota, A. Strancar, M. Hočevar, and J. Rakun. 2012. Programmable ultrasonic sensing system for targeted spraying in orchards. Sensors 12(11):15500-15519.

Superb Horticulture. 1994. Model 1000 CS parts manual. AgTec Crop Sprayer, Plymouth, IN.

Sutton, T.B., H.S. Aldwinckle, A.M. Agnello, and J.F. Walgenbach. 2014. Compendium of apple and pear diseases and pests. Amer. Phytopathol. Soc. (APS Press), St. Paul, MN.

Syngenta, A.G. 2002. Water-sensitive paper for monitoring spray distributions. Syngenta Crop Protection. Basel, Switzerland.

Travis, J., W. Skroch, and T. Sutton. 1987a. Effect of canopy density on pesticide deposition and distribution in apple trees. Plant Dis. 71:613615.

Travis, J., W. Skroch, and T. Sutton. 1987b. Effects of travel speed, application volume, and nozzle arrangement on deposition and distribution of pesticides in apple trees. Plant Dis. 71:606-612.

USDA. 2011. 2009 nursery and floriculture chemical use survey. $<$ https://www.nass.usda.gov/Data and_Statistics/Pre-Defined_Queries/2009_Nursery_and_Floriculture_Chem_Usage/index.php $>$.

USDA. 2018. 2017 fruits chemical use survey. $<$ https://www.nass.usda.gov/Data_and_Statistics/ Pre-Defined_Queries/2017_Fruit_Chem_Usage/ index.php>

Walklate, P., J. Cross, G. Richardson, D. Baker, and R. Murray. 2003. A generic method of pesticide dose expression: Application to broadcast spraying of apple trees. Ann. Appl. Biol. 143(1):11-23.

Witton, J.T., M.D. Pickering, T. Alvarez, M. Reed, G. Weyman, M.E. Hodson, and R. Ashauer. 2018. Quantifying pesticide deposits and spray patterns at micro-scales on apple (Malus domesticus) leaves with a view to arthropod exposure. Pest Mgt. Sci. 74(12):2884 2893.

Yeager, T., T. Bilderback, C. Boyer, M. Chappell, G. Fain, D. Fare, C. Gilliam, B. Jackson, J. Lea-Cox, A. Lebude, A. Niemiera, J. Owen, J. Ruter, K. Tilt, S. Warren, S. White, T. Whitwell, and R. Wright. 2013. Best management practices: Guide for producing 
nursery crops. Southern Nursery Assn., Acworth, GA.

Zhu, H., R. Derksen, H. Guler, C. Krause, and H. Ozkan. 2006. Foliar deposition and off-target loss with different spray techniques in nursery applications. Trans. ASABE 49(2):325-334.

Zhu, H., H. Liu, Y. Shen, H. Liu, and R. Zondag. 2017. Spray deposition inside multiple-row nursery trees with a laser-guided sprayer. J. Environ. Hort. 35(1):13-23.

Zhu, H., M. Salyani, and R.D. Fox. 2011a. A portable scanning system for evaluation of spray deposit distribution. Comput. Electron. Agr. 76(1):38-43.

Zhu, H., R. Zondag, R. Derksen, M. Reding, and C. Krause. 2008. Influence of spray volume on spray deposition and coverage within nursery trees. J. Environ. Hort. 26(1):51-57.

Zhu, H., R.H. Zondag, C.R. Krause, J. Merrick, and J. Daley. 2011b. Reduced use of pesticides for effective controls of arthropod pests and plant diseases. J. Environ. Hort. 29(3):143151 